\title{
Blade Deterioration in a Gas Turbine Engine*
}

\author{
W. TABAKOFF ${ }^{a}, \uparrow$, A. HAMED ${ }^{a}$ and V. SHANOV ${ }^{b}$ \\ a Department of Aerospace Engineering and Engineering Mechanics, University of Cincinnati, \\ Cincinnati, OH 45221, USA; ${ }^{\mathrm{b}}$ Technological University of Sofia, Bulgaria
}

(Received 27 February 1997; In final form 6 March 1997)

\begin{abstract}
A study has been conducted to predict blade erosion of gas turbine engines. The blade material erosion model is based on three dimensional particle trajectory simulation in the three-dimensional turbine flow field. The trajectories provide the special distribution of the particle impact parameters over the blade surface. A semi-empirical erosion model, derived from erosion tests of material samples at different particulate flow conditions, is used in the prediction of blade surface erosion based on the trajectory impact data. To improve the blade erosion resistance and to decrease the blade deterioration, the blades must be coated. For this purpose, an experimental study was conducted to investigate the behavior of rhodium platinum aluminide coating exposed to erosion by fly ash particles. New protective coatings are developed for erosion and thermal barrier. Chemical vapor deposition technique (CVD) was used to apply the ceramic TiC coatings on INCO 718 and stainless steel 410. The erosive wear of the coated samples was investigated experimentally by exposing them to particle laden flow at velocities from 180 to $305 \mathrm{~m} / \mathrm{s}$ and temperatures from ambient to $5^{\circ 38} \mathrm{C}$ in a specially designed erosion wind tunnel. Both materials (INCO 718 and stainless steel 410) coated with CVD TiC showed one order of magnitude less erosion rate compared to some commercial coatings on the same substrates.
\end{abstract}

Keywords: Particulated flow, Erosion, Engine deterioration

\section{INTRODUCTION}

Gas and steam turbines operate in environments where the ingestion of solid particles is inevitable. In industrial applications and power generation, such as coal-burning boilers, fluidized beds and gas turbines, solid particles are produced during the combustion of heavy oils, synthetic fuels and pulverized coal. In commercial and military aircraft and naval installations, some of the mechanisms that cause solid particle ingestion are vortices generated during landing and takeoff, sand storms, volcanic ash and thrust reverser efflux at low speed which blows sand, ice and dust into the engines. In steam turbines, the solid particles are principally boiler scale, mainly iron oxide, that break off and become entrained in the steam. Filters and separators can remove a large percentage of the solid particles, but significant amounts of small particles still pass through and enter the engines.

* This paper was originally presented at ISROMAC-6.

${ }^{\dagger}$ Corresponding author. 
Due to their higher inertia, the solid particles deviate from the flow streamlines, impact the blade surfaces and cause severe erosion damage. This damage is manifested by pitting and cutting of the blade leading and trailing edges and an increase in the blade surface roughness. The overall effects of the above phenomena are to increase the pressure loss and to change the blade geometry. Continued operation under particulate flow conditions adversely affects the performance of the engines, as well as their lives, and can be detrimental to their reliability.

Gas turbine materials have developed rapidly beyond the conventional ferrous alloys consisting of steels and stainless steels of various compositions. Several nickel and cobalt base alloys have been developed and have been used widely in the hot section of gas turbines in order to meet complex high temperature corrosion phenomena. Chromium additions have been used and they contribute to an improvement in high temperature strength and oxidation resistance. Protective coatings have been used to enhance superalloy resistance to hot erosion-corrosion. Some of the most widely used coatings are diffusion coatings, overlay coatings, plasma sprayed coatings and ion implantation coatings. Chromium, platinum, radium and silicon additions have been used in order to improve the erosion-corrosion resistance of the coatings.

Although physical, chemical and mechanical properties of turbine alloys and coatings are documented satisfactorily, there is insufficient data about their rebound and erosion behavior, especially at high temperatures. Therefore an experimental high temperature facilities were built at the University of Cincinnati sponsored by DOD, DOE and NSF for performing experimental study on "Turbomachinery Erosion and Particulate Flow Rebound" at high temperatures. Different types of solid particles were investigated such as: quartz sand, fly ash, volcanic ash, iron chromite, different types of catalyst and many others. The experimental results show the effects of the main erosion parameters, namely, velocity, temperature and impact angle, on the erosion rates. Erosion models have been developed for the tested materials based on the experimental erosion data and restitution parameters.

Ceramic coatings such as refractory metal carbides, nitrides, and oxides have been investigated very intensively because of their high resistance to erosion and corrosion. Titanium carbide (TiC), titanium nitride (TiN), and alumina $\left(\mathrm{Al}_{2} \mathrm{O}_{3}\right)$, are widely used as wear resistance coatings for cemented carbide cutting tools. These coating materials and a bulk substrate, being tough enough to stop cracks generated at the surface and hard enough to prevent plastic deformation are attractive for design of turbomachinery components operating in a particulate flow environment.

The erosion resistance of ceramic coatings is strongly dependent on the coating process and on the substrate material [Qureshi and Tabakoff (1988), and Tabakoff (1989)]. Two basic coating techniques have been developed throughout the years: chemical vapor deposition (CVD) and physical vapor deposition (PVD). Our previous works demonstrated the excellent protection provided by CVD coatings for cemented tungsten carbide exposed to particulate flow environment [Shanov, Tabakoff and Metwally (1992), and Shanov, Tabakoff and Hamed (1994)]. In this study, two substrate materials, INCO 718 and stainless steel 410 , both coated with CVD titanium carbide, were investigated.

\section{ANALYSIS}

The equations governing the particle motion in the turbomachinery flow field written in cylindrical polar coordinates relative to a frame of reference fixed with respect to the rotating blade are:

$$
\begin{gathered}
\frac{\mathrm{d}^{2} \mathrm{r}_{\mathrm{p}}}{\mathrm{d} \tau^{2}}=\mathrm{F}_{\mathrm{r}}+\mathrm{r}_{\mathrm{p}}\left(\frac{\mathrm{d} \theta_{\mathrm{p}}}{\mathrm{d} \tau}+\omega\right)^{2}, \\
\mathrm{r}_{\mathrm{p}} \frac{\mathrm{d}^{2} \theta_{\mathrm{p}}}{\mathrm{d} \tau^{2}}=\mathrm{F}_{\theta}-2 \frac{\mathrm{d} \mathrm{r}_{\mathrm{p}}}{\mathrm{d} \tau}\left(\frac{\mathrm{d} \theta_{\mathrm{p}}}{\mathrm{d} \tau}+\omega\right), \\
\frac{\mathrm{d}_{2} \mathrm{z}_{\mathrm{p}}}{\mathrm{d} \tau^{2}}=\mathrm{F}_{\mathrm{z}},
\end{gathered}
$$


where $r_{p}, \theta_{p}, z_{p}$ define the particle location in cylindrical polar coordinates, and $\omega$ is the blade angular velocity. The centrifugal force and Coriolis acceleration are represented by the last term on the right hand side of equations (1) and (2). The first term on the right hand side of equations (1) through (3) represents the force of interaction between the two phases, per unit mass of particles.

Under the particulate flow conditions in turbomachines, the effects of the forces due to gravity and interparticle interactions are negligible, compared to those due to the aerodynamic and centrifugal forces. The force of interaction between the two phases is dominated by the drag due to the relative velocity between the solid particles and the gas flow. The force of interaction per unit mass of solid particles is given by

$$
\begin{aligned}
& \overline{\mathrm{F}}=\frac{3}{4} \frac{\rho}{\rho_{\mathrm{p}}} \frac{\mathrm{C}_{\mathrm{D}}}{\mathrm{d}} {\left[\left(\mathrm{V}_{\mathrm{r}}-\frac{\mathrm{dr}_{\mathrm{p}}}{\mathrm{d} \tau}\right)^{2}+\left(\mathrm{V}_{\theta}-\mathrm{r}_{\mathrm{p}} \frac{\mathrm{d} \theta_{\mathrm{p}}}{\mathrm{d} \tau}\right)^{2}\right.} \\
&\left.+\left(\mathrm{V}_{\mathrm{z}}-\frac{\mathrm{d} \mathrm{z}_{\mathrm{p}}}{\mathrm{d} \tau}\right)^{2}\right]^{1 / 2}\left(\overline{\mathrm{V}}-\overline{\mathrm{V}}_{\mathrm{p}}\right),
\end{aligned}
$$

where $\overline{\mathrm{V}}$ and $\overline{\mathrm{V}}_{\mathrm{p}}$ are the gas and particle velocities relative to the blade, $\mathrm{V}_{\mathrm{r}}, \mathrm{V}_{\theta}, \mathrm{V}_{\mathrm{z}}$, represent the relative gas velocity components in the radial, circumferential and axial directions, respectively, and $\rho, \rho_{\mathrm{p}}$ are the gas and solid particle material densities, $d$ the particle diameter, and $C_{D}$ the particle drag coefficient. This coefficient is dependent on the Reynolds number, which is based on the relative velocity between the particle and the gas. The empirical relations used to fit the drag curve over a wide range of Reynolds numbers were discussed by Tabakoff and Hamed (1986).

\section{Particle Trajectories}

The particle trajectory calculations consist of the numerical integration of the equations (1)-(3) in the flow field, up to the point of blade, hub, or tip impact. The magnitude and direction of particle rebounding velocity after these impacts are dependent on the impacting conditions and the particle and surface materials. The particle rebounding conditions are determined from empirical correlations based on the experimental measurements of the particle impact and rebound velocities, $V_{1}$ and $\mathrm{V}_{2}$ correspondingly near the metal surface using Laser Doppler Velocimetry. The LDV measurements are obtained near the material samples set at various angles relative to the particle laden flow in a special tunnel described by Tabakoff [1992]. The restitution ratios were found to be mainly dependent upon the impingement angle [Tabakoff and Malak (1985)] for a given particle-material combination.

The following empirical correlations were obtained for mean value of fly ash particles restitution parameters in terms of the impingement angle [Tabakoff (1990a)].

For MAR-M246 Alloy:

$$
\begin{aligned}
\mathrm{e}_{\mathrm{T}}=\frac{\mathrm{V}_{\mathrm{T} 2}}{\mathrm{~V}_{\mathrm{T} 1}}= & 1.00-0.00832249 \beta_{1}-8.09523 * 10^{-5} \beta_{1}^{2} \\
& +1.78601 * 10^{-6} \beta_{1}^{2},
\end{aligned}
$$

$$
\begin{aligned}
\mathrm{e}_{\mathrm{N}}=\frac{\mathrm{V}_{\mathrm{N} 2}}{\mathrm{~V}_{\mathrm{N} 1}}= & 1.00-0.00809841 \beta_{1}-0.00122611 \beta_{1}^{2} \\
& +2.30864 * 10^{-5} \beta_{1}^{3}-1.2922 * 10^{-7} \beta_{1}^{4},
\end{aligned}
$$

where $\mathrm{V}_{\mathrm{T}}$ and $\mathrm{V}_{\mathrm{N}}$ are the tangential and the normal velocity components, and $\beta_{1}$ particle impingement angles.

\section{For Rhodium Platinum Aluminide Coating (RT22B):}

$$
\begin{aligned}
\mathrm{e}_{\mathrm{T}}=\frac{\mathrm{V}_{\mathrm{T} 2}}{\mathrm{~V}_{\mathrm{T} 1}}= & 1.0-0.0217 \beta_{1}+4.0459 * 10^{-4} \beta_{1}^{2} \\
& -1.882 * 10^{-6} \beta_{1}^{3}, \\
\mathrm{e}_{\mathrm{N}}=\frac{\mathrm{V}_{\mathrm{N} 2}}{\mathrm{~V}_{\mathrm{N} 1}}= & 1.0-0.03624 \beta_{1}+8.0027 * 10^{-4} \beta_{1}^{2} \\
& -5.5885 * 10^{-6} \beta_{1}^{3} .
\end{aligned}
$$


The particle trajectory after each blade impact and the particle distribution over the blade row are influenced by the rebound correlations and the local turbine blade geometry as reported by Hussein and Tabakoff (1973). The blade airfoil, hub and casing geometry must therefore be accurately represented in the trajectory analysis as it strongly influences the predicted particle dynamics.

\section{Turbine Blade Passage Flow Fields}

The large flow turning angles generally encountered in turbine blading produce large pitchwise as well as radial and axial flow field variations. The description of the 3-D flow field in the blade passage is required for accurate prediction of the particle trajectories. In the present study, the flow field in a blade passage is synthesized from a number of blade-to-blade stream surface solutions using Katsanis' code [Katsanis (1965) and (1977)].

\section{Blade Erosion Model}

The erosion model consists of a semi-empirical equation [Tabakoff (1984)] in which the values of the constants are determined from the experimental measurements.

$$
\begin{aligned}
\varepsilon= & \mathrm{C}_{1}\left(\frac{\mathrm{V}_{1}}{100}\right)^{\mathrm{N} 1} \sin ^{\mathrm{N} 2} \beta_{1} \cos ^{\mathrm{N} 3} \beta_{1}\left[1-\mathrm{e}_{\mathrm{T}}^{2}\right] \\
& +\mathrm{C}_{2}\left(\frac{\mathrm{V}_{1}}{100}\right)^{\mathrm{N} 4} \sin ^{2} \beta_{1}\left[1-\mathrm{e}_{\mathrm{N}}^{2}\right] .
\end{aligned}
$$

In the above equation, the erosion mass parameter, $\epsilon$, represents the ratio of the eroded mass of target material to the mass of impinging particles; $\mathrm{V}_{1}$ and $\beta_{1}$ represent the impact velocity $(\mathrm{m} / \mathrm{s})$ and impact angle (degree) respectively, and $\mathrm{e}_{\mathrm{T}}$ and $\mathrm{e}_{\mathrm{N}}$ are the tangential and normal restitution ratios given by equations (5) and (6) for M246 and by equations (7) and (8) for RT22B.

The values of constants $\mathrm{C} 1, \mathrm{C} 2$ and the exponents $\mathrm{N} 1, \mathrm{~N} 2, \mathrm{~N} 3$ and $\mathrm{N} 4$ are given in the following table for fly ash particles impacting samples of the blade materials under investigation [Tabakoff et al. (1990b)].
TABLE I

\begin{tabular}{lcc}
\hline & MAR-M246 alloy & $\begin{array}{c}\text { Rhodium platinum alumi- } \\
\text { nide coating (RT22B) }\end{array}$ \\
\hline C1 & 0.41861 & 0.02077 \\
C2 & 0.02739 & 0.00012 \\
N1 & 2.32 & 3.70 \\
N2 & 0.60 & 1.5 \\
N3 & 2.25 & 4.3 \\
N4 & 2.94 & 3.73 \\
\hline
\end{tabular}

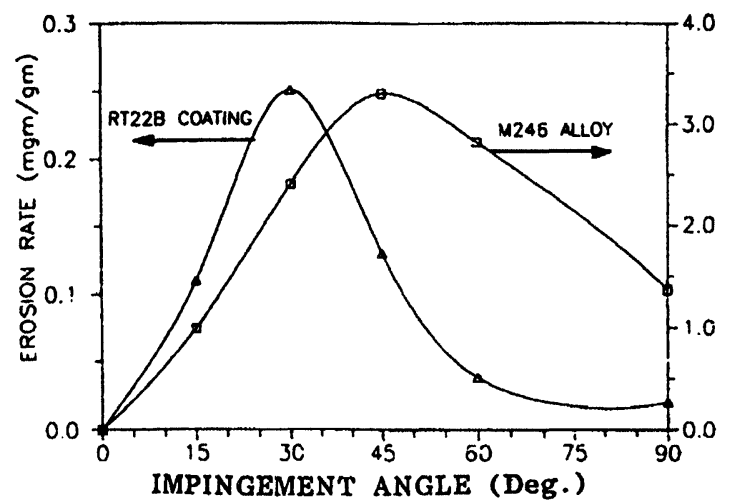

FIGURE 1 Erosion rate variation with the impingent angles at $\mathrm{V}_{1}=366 \mathrm{~m} / \mathrm{s}$ and $\mathrm{T}=815^{\circ} \mathrm{C}$.

Figure 1 gives a graphic presentation of the erosion characteristics of the blade material and coating under investigation. According to the experimental data, the coating reduces the erosion rate by an order of magnitude. Both curves exhibit typical ductile material erosion behavior, with maximum erosion rate of $35^{\circ}-50^{\circ}$ for MAR-M246 and $30^{\circ}$ for RT22B. The computation of blade erosion combines the model for the mass erosion parameter (9) with the results of the particle trajectory calculations. The latter provides the impact velocities, impingement angles and impact locations for a large number of particle trajectories.

\section{CALCULATION PROCEDURE}

Two separate computer codes are used, one for calculating particle trajectories in the blade passages and another for predicting the blade erosion. The output of the particle trajectory code consists 
of three files. The first file provides the input for particle trajectory plots. The second file contains all particle exit conditions from a given blade row. It is used as input to provide the initial conditions for the particle trajectories in the following blade row. The data are first adapted to a new frame of reference, which is fixed in each blade row. The third file contains all computed particle impact data, including the impact locations, the impact velocity, and impingement angle relative to the blade surface.

The code for blade surface erosion computations uses as input the third particle trajectory output file containing the blade impact data. The appropriate empirical equations for the blade material erosion and the blade surface geometry are also needed in the blade erosion simulations. The output from this program includes the blade erosion pattern, as well as the distribution of the impact velocity, impingement angles, and the frequency of particle blade surface impacts, over the blade pressure and suction surfaces.

\section{RESULTS AND DISCUSSION}

The particle trajectory and blade erosion analysis were carried out through an industrial axial flow turbine. The blade impact data from the trajectories of 5,000 ingested $15 \mu \mathrm{m}$ particles were used to obtain the erosion results. The trajectories were simulated in the gas turbine of standard inlet air equivalent conditions at $10,000 \mathrm{rpm}$ and $50 \mathrm{~kg} / \mathrm{s}$ weight flow. At the turbine inlet the particles were assumed to enter axially at the same velocity as the gas, and they were distributed in proportion to the mass flux, using random number generators.

Typical particle trajectories for MAR-M246 blade material and blade erosion patterns are presented for the same blade material with and without RT22B (rhodium platinum aluminide) coating. In addition, the particle blade impact data that influence erosion, including the impact frequency, impact velocity, and impingement angle distribution over the blade, are presented to gain insight into the blade erosion phenomena.

\section{Particle Trajectories}

The particle trajectories were computed for both coated and uncoated blades, but no significant differences were observed between the two cases.

\section{Particle Impact Locations}

The particle impact locations on the blade suction and pressure surfaces are shown in Figs. 2 and 3, respectively. Comparing the two figures, one can see that in general the stationary blade pressure surfaces are subjected to many more impacts than the suction surfaces. Figure 2 shows that in the guide vane, the blade pressure surface impacts increase toward the trailing edge with no radial variation in the impact pattern. The stator blade impacts are more evenly distributed over the pressure surface with the exception of a reduced impact zone near the leading edge. The stationary blades suction impacts are seen to be mostly restricted to the zone near the leading edge (Fig. 3) with most of the blade suction surface not subject to any particle impacts. The rotor blade suction surface is subjected to more impacts near the tip because of the

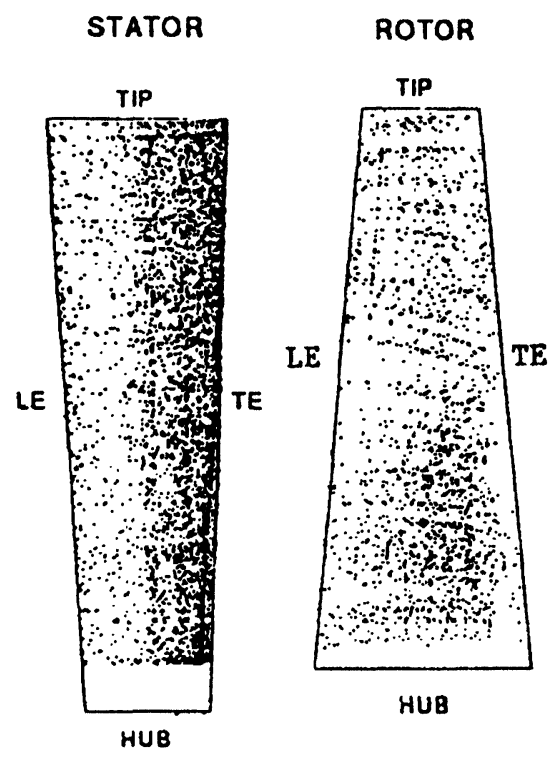

FIGURE 2 Particle impact location for stator and rotor on the blade pressure surface. 


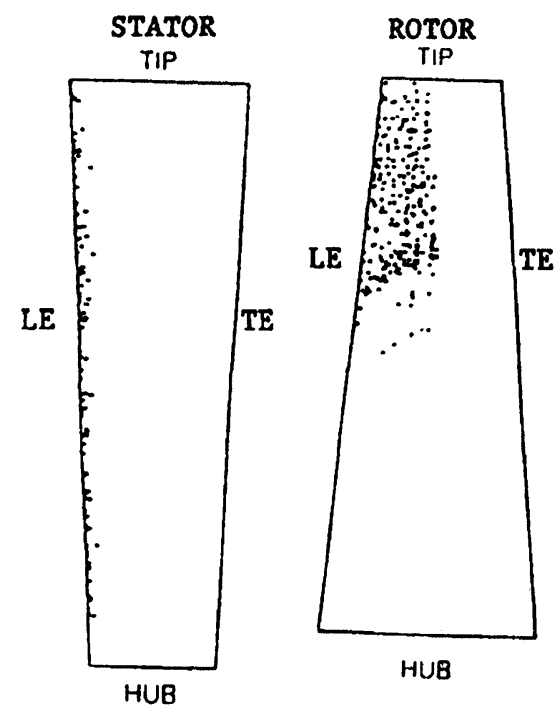

FIGURE 3 Particle impact locations on the blade suction surface.

negative incidence angle of the particles at the rotor inlet (Fig. 3).

\section{Blade Erosion}

The blade erosion prediction is based on the particle computed impact data as determined from the particle trajectory calculations, and erosion model [Eq. (9)]. The blade mass erosion rate (mgm/ $\mathrm{gm} / \mathrm{m}^{2}$ ) is defined as the blade mass removal per unit area of the blade surface per unit mass of ingested particles. Since the stationary blade suction surfaces are subjected to fewer impacts, their erosion is insignificant. Thus, the erosion prediction results are presented only for pressure surfaces of the fixed blades.

Figure 4 shows the distributions of the predicted stator and rotor pressure surfaces impact frequency, impact velocity and impact angles. The surface impact frequency is defined as the number of particle impacts per unit area of the blade surface per unit mass ingested particles $\left(\mathrm{gm} / \mathrm{cm}^{2}\right)$. The impact velocities and impingement angles are expressed in $(\mathrm{m} / \mathrm{s})$ and (degree). The parameters for stator from hub to tip are not changing too much, but for rotor they are. Figures 5 and 6 show the stator and rotor blade pressure surfaces erosion for uncoated and coated blades. From Figs. 5 and 6, it is evident that coatings reduce the magnitude of the stator and rotor blade pressure side erosion.

The estimated stator and blade overall erosion characteristics (15 $\mu \mathrm{m}$ fly ash) for M246 alloy and rhodium platinum aluminide coating (RT22B) are shown in Tables II and III.

\section{Impact Angle Effect on the Erosion Rate for TiC Coatings}

An experimental study was conducted to investigate the behavior of coated metal substrates exposed to erosion by chromite particles. Chemical vapor deposition technique (CVD) was used to apply titanium carbide (TiC) on nickel based alloy INCO 718 and stainless steel 410. Another group of specimens made of the same substrate materials was subjected to surface treatment by nitriding in glow discharge plasma (ion nitriding). The erosive wear of the samples was investigated experimentally by exposing them to particle laden flow at velocities from 180 to $305 \mathrm{~ms}^{-1}$, temperatures from ambient to $538^{\circ} \mathrm{C}$ and impingement angles from 20 through 90 degrees in a specially designed erosion wind tunnel. The erosion results show the effect of the velocity, temperature and the impingement angle on the erosion rate.

The effect of the impingement angle on the erosion rate of the tested CVD coatings is presented in Figs. 7 and 8. Inspection of Fig. 7 shows that the TiC coating erosion rate increases with the impingement angle and reaches a maximum at $90^{\circ}$ for both metal substrates. The TiC coating reveals better protection on stainless steel 410 substrate than on INCO 718 substrate when it was impacted by particle mass of $20 \mathrm{~g}$ chromite powder. Inspection of the eroded surfaces shows that the coating does not have any cracks and plastic deformations. This behavior, we believe, is related to the fine grained structure of the coating and its good adhesion to the substrate. TiC coating provides excellent erosion protection to INCO 718 and stainless steel 410 . 

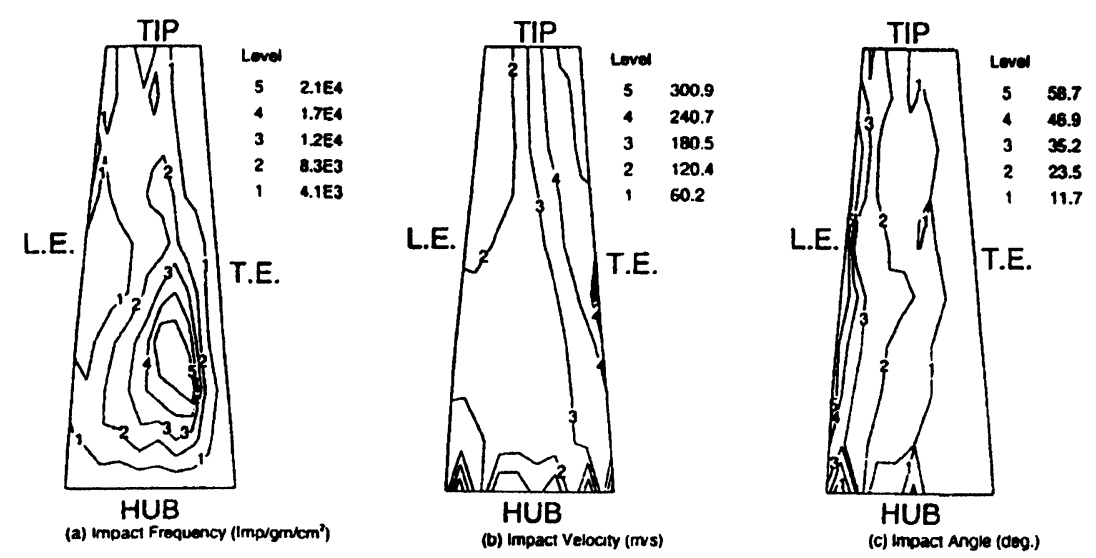

FIGURE 4 Rotor pressure surface impact frequencies, impact velocities, and impact angles.
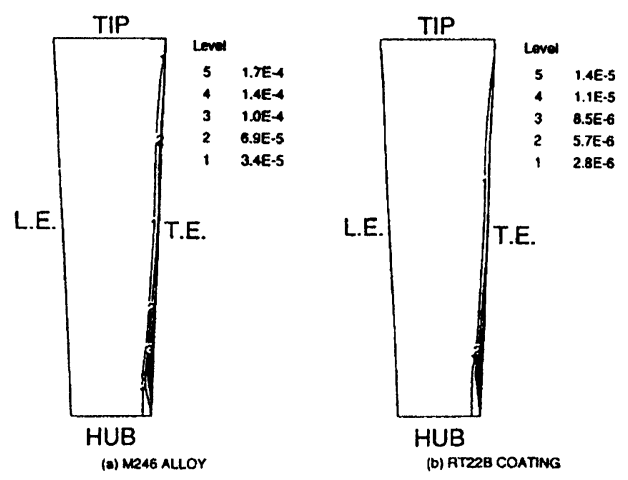

FIGURE 5 Rotor suction surface erosion rate $\left(\mathrm{mg} / \mathrm{g} / \mathrm{cm}^{2}\right)$ for M246 and RT22B coating.

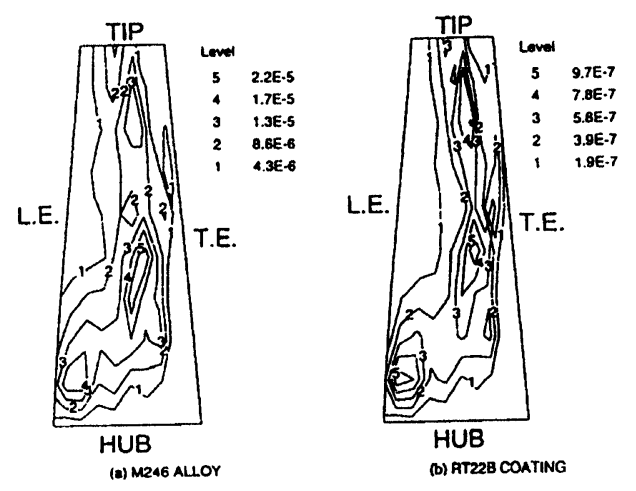

FIGURE 6 Rotor pressure surface erosion rate $(\mathrm{mg} / \mathrm{gm}$ $\mathrm{cm}^{2}$ ) for M246 and RT22B coatings.

TABLE II

\begin{tabular}{|c|c|c|c|}
\hline & Materials & M246 alloy & RT22B coating \\
\hline Pressure side & $\begin{array}{l}\text { Total erosion }(\mathrm{mgm} / \mathrm{gm}) \\
\text { Total impact }(\mathrm{imp} / \mathrm{gm}) \\
\text { Surface area }\left(\mathrm{cm}^{2}\right)\end{array}$ & $1.55 \times 10^{-3}$ & $1.015 \times 10^{-4}$ \\
\hline Suction side & $\begin{array}{l}\text { Total erosion }(\mathrm{mgm} / \mathrm{gm}) \\
\text { Total impact }(\mathrm{imp} / \mathrm{gm}) \\
\text { Surface area }\left(\mathrm{cm}^{2}\right)\end{array}$ & $8.09 \times 10^{-6}$ & $6.34 \times 10^{-8}$ \\
\hline
\end{tabular}

TABLE III

\begin{tabular}{llcc}
\hline & \multicolumn{1}{c}{ Materials } & M246 alloy & RT22B coating \\
\hline Pressure side & Total erosion $(\mathrm{mgm} / \mathrm{gm})$ & $8.64 \times 10^{-4}$ & \multicolumn{2}{c}{$3.99 \times 10^{-5}$} \\
& Total impact $(\mathrm{imp} / \mathrm{gm})$ & & $8.19 \times 10^{5}$ \\
& Surface area $\left(\mathrm{cm}^{2}\right)$ & & 143.19 \\
Suction side & Total erosion $(\mathrm{mgm} / \mathrm{gm})$ & $1.62 \times 10^{-5}$ & \multicolumn{2}{c}{$1.86 \times 10^{-7}$} \\
& Total impact $(\mathrm{imp} / \mathrm{gm})$ & & \multicolumn{2}{c}{$1.25 \times 10^{5}$} \\
& Surface area $\left(\mathrm{cm}^{2}\right)$ & & 389.73 \\
\hline
\end{tabular}




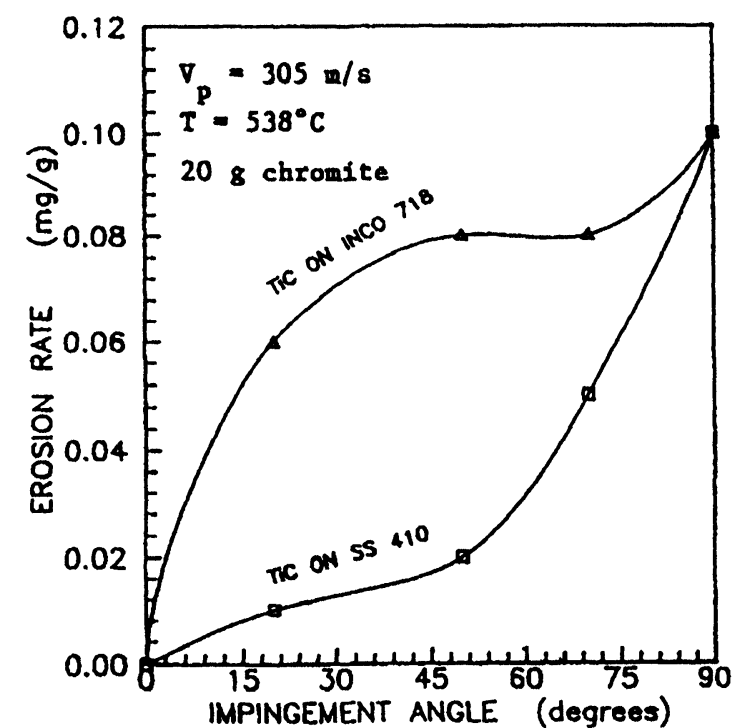

FIGURE 7 Titanium carbide coating erosion rate vs. impingement angle.

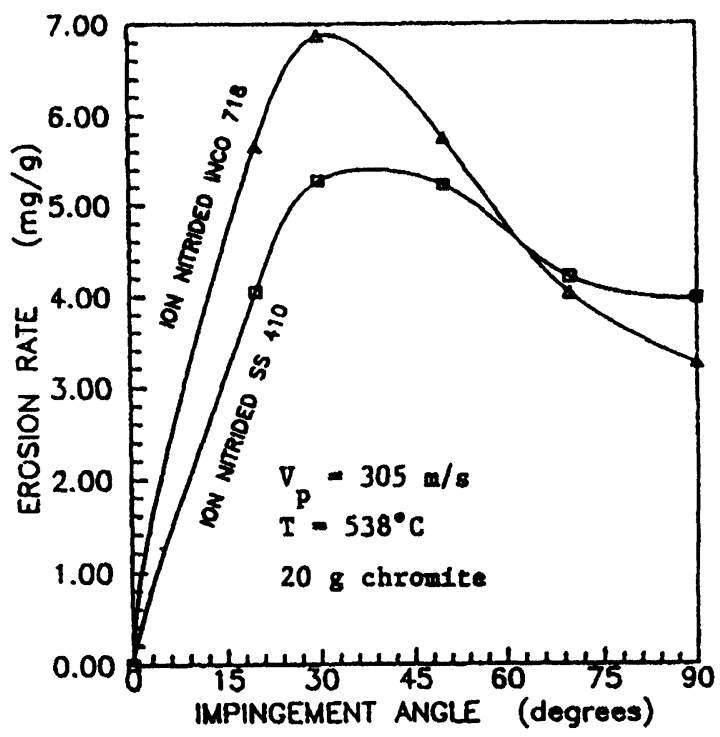

FIGURE 8 Erosion rate variation of ion nitrided metal substrates with impingement angle.

Variation of the erosion rate with the impact angle for the ion nitrided substrates used in this study is shown in Fig. 8. The erosion rates for both specimens pass through a maximum at $30^{\circ}$ impact angle. These patterns indicate the ductile nature of the surface nitrided layers. Similar behavior showed uncoated INCO 718 and stainless steel 410 exposed to particulate flow environment. The ion nitrided specimens did not reveal any improved erosion resistance compared to the uncoated metal substrates, although the increased surface hardness by the nitriding process. It seems that the glow discharge plasma has affected the substrate in a negative way. Similar to the ion implantation process, the forced diffusion into the substrate could create structure defect layers. A detailed study is required which should involve surface healing after the ion nitriding by a proper thermal treatment.

\section{CONCLUSIONS}

The presented results provide a detailed description of particle trajectories and blade surface erosion pattern through an expander turbine for both coated and uncoated blades. The results of particle trajectory computations show no significant variation in the computed three-dimensional trajectories for coated and uncoated blades, which indicates the insignificant effect of coating on the particle dynamics through the turbine blade rows. The blade surface erosion results show that the rotor represents the most critical blade row erosion. In the stator blade, the maximum erosion is at the trailing edge near the hub. The maximum erosion at the outmost radial locations and the erosion pattern is quite similar to the impact frequency distribution over the blade surfaces. The coating has a very strong effect on the erosion levels. The maximum erosion rates for the coated blade rows are, at least, one order of magnitude less than the uncoated ones, since the coated blade life will be one order of magnitude longer. In addition, this study demonstrated that the CVD titanium carbide coating provides excellent erosion protection for INCO 718 and stainless steel 410 when subjected to impact by chromite particles at elevated temperatures. 


\section{Acknowledgements}

This research work was sponsored by NSF International Cooperative Activities, Washington, D.C. under NSF Grant INT-9204963. We would like to thank Mr. Jong-Du Jun for his assistance preparing the figures. The CVD coating was partially supported by the Ministry of Science and Education, Bulgaria.

\section{NOMENCLATURE}

$\mathrm{C}_{\mathrm{D}} \quad$ particle drag coefficient

d particle diameter

e restitution ratio

F force of interaction between the gas and the particle

$\mathrm{r}$ radial distance from the turbomachine axis

$\mathrm{V}$ gas relative velocity

$\mathrm{V}_{1} \quad$ impacting particle velocity

$\mathrm{V}_{\mathrm{p}} \quad$ particle relative velocity

$\mathrm{z} \quad$ axial coordinate

$\beta_{1} \quad$ impacting angle

$\epsilon \quad$ erosion rate

$\theta \quad$ angular coordinate

$\rho \quad$ gas density

$\rho_{\mathrm{p}} \quad$ particle density

$\omega \quad$ rotor speed (radians/s)

\section{References}

Hussein, M.F. and Tabakoff, W. (1973) "Dynamic Behavior of Solid Particles Suspended by Polluted Flow in a Turbine Stage," Journal of Aircraft, Vol. 10, pp. 434-440.
Katsanis, T. (1965) "Fortran Program for Calculating Transonic Velocities on a Blade-to-Blade Stream Surface of a Turbomachine," NASA TND-2809.

Katsanis, T. and McNally, W. D. (1977) "Revised Fortran Program for Calculating Velocities and Streamlines in the Hub-Tip Mid Channel Stream Surface of an Axial, Radial, or Mixed Flow Turbomachine or Annular Duct, Vols. 1 and 2," NASA TND-8430 and NASA TND-8431.

Qureshi, J. and Tabakoff, W. (1988) "The Influence of Coating Processes and Process Parameters on Surface Erosion Resistance and Substrate Fatigue Strength," Surface \& Coatings Technology, 36, 433 .

Shanov, V., Tabakoff, W. and Hamed, A. (1994) "Erosion Behavior of Thermally Treated Pyrophyllite Coated with Titanium Carbide," Surface and Coatings Technology, 68/69,92.

Shanov, V., Tabakoff, W. and Metwally, M. (1992) "Erosive Wear of CVD Ceramic Coatings Exposed to Particulate Flow," Surface and Coatings Technology, 54/55, 25.

Tabakoff, W. (1992) "High Temperature Erosion Resistance of Coatings for Use in Turbine Engines," Surface and Coatings Technology, 52, pp. 65-79.

Tabakoff, W. (1989) "Investigation of Coatings at High Temperature for Use in Turbomachinery," Surface and Coatings Technology, 39/40, 97.

Tabakoff, W. (1984) "Review - Turbomachinery Performance Deterioration Exposed to Solid Particles Environments," ASME Journal of Fluids Engineering, Vol. 106, pp. 106-125.

Tabakoff, W. and Hamed, A. (1986) "The Dynamics of Suspended Solid Particles in a Two-Stage Gas Turbine," ASME Journal of Turbomachinery, Vol. 108, pp. 298-302.

Tabakoff, W., Hamed, A., Metwally, M., Yeuan, J. and Pasin, M. (1990a) "Study of Particle Rebound Characteristics and Material Erosion at High Temperature," Progress Technical Report, Fossil Energy Materials Program, U.S. Department of Energy, ORNL/Sub/84-89628/04, November.

Tabakoff, W., Hamed, A., Metwally, M., Yeuan, J. and Pasin, M. (1990b) "Study of Particle Rebound Characteristics and Material Erosion at High Temperature," Final Technical Report, Fossil Energy Materials Program, U.S. Department of Energy, ORNL/Sub/84-89628/03, October.

Tabakoff, W., Malak, M.F. and Hamed, A. (1985) "Laser Measurements of Solid Particles Rebound Parameters Impacting on 2024 Aluminum and 6Al-4V Titanium Alloys," Paper No. AIAA 85-1570. 


\section{ait \\ ENERGY MATERIALS}

M A N E Y publishing

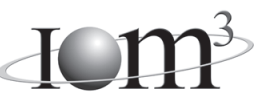

\section{Materials Science \& Engineering for Energy Systems}

Maney Publishing on behalf of the Institute of Materials, Minerals and Mining

The Institute of Materials, Minerals \& Mining

Economic and environmental factors are creating ever greater pressures for the efficient generation, transmission and use of energy. Materials developments are crucial to progress in all these areas: to innovation in design; to extending lifetime and maintenance intervals; and to successful operation in more demanding environments. Drawing together the broad community with interests in these areas, Energy Materials addresses materials needs in future energy generation, transmission, utilisation, conservation and storage. The journal covers thermal generation and gas turbines; renewable power (wind, wave, tidal, hydro, solar and geothermal); fuel cells (low and high temperature); materials issues relevant to biomass and biotechnology; nuclear power generation (fission and fusion); hydrogen generation and storage in the context of the 'hydrogen economy'; and the transmission and storage of the energy produced.

As well as publishing high-quality peer-reviewed research, Energy Materials promotes discussion of issues common to all sectors, through commissioned reviews and commentaries. The journal includes coverage of energy economics and policy, and broader social issues, since the political and legislative context influence research and investment decisions.

\section{CALL FOR PAPERS}

Contributions to the journal should be submitted online at http://ema.edmgr.com

To view the Notes for Contributors please visit: www.maney.co.uk/journals/notes/ema

Upon publication in 2006, this journal will be available via the Ingenta Connect journals service. To view free sample content online visit: www.ingentaconnect.com/content/maney

For further information please contact:

Maney Publishing UK

Tel: +44 (0)113 2497481 Fax: +44 (0)1132486983 Email: subscriptions@maney.co.uk

or

Maney Publishing North America

Tel (toll free): 8662975154 Fax: 6173546875 Email: maney@maneyusa.com

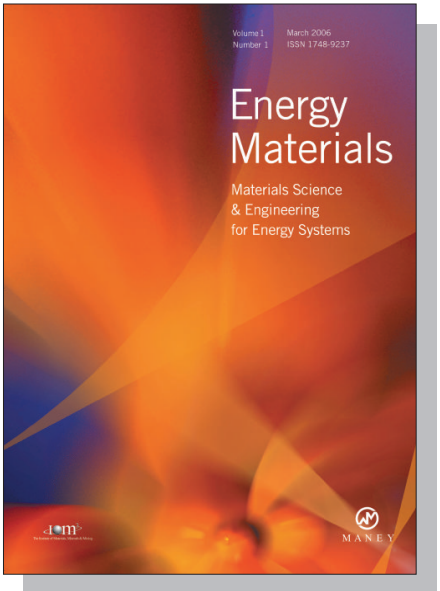

EDITORS

Dr Fujio Abe

NIMS, Japan

Dr John Hald, IPL-MPT, Technical University of Denmark, Denmark

Dr R Viswanathan, EPRI, USA

\section{SUBSCRIPTION INFORMATION}

Volume 1 (2006), 4 issues per year

Print ISSN: 1748-9237 Online ISSN: 1748-9245

Individual rate: $£ 76.00 / U S \$ 141.00$

Institutional rate: $£ 235.00 /$ US $\$ 435.00$

Online-only institutional rate: $£ 199.00 / U S \$ 367.00$

For special $\mathrm{IOM}^{3}$ member rates please email

subscriptions@maney.co.uk

\section{For further information or to subscribe online please visit www.maney.co.uk}



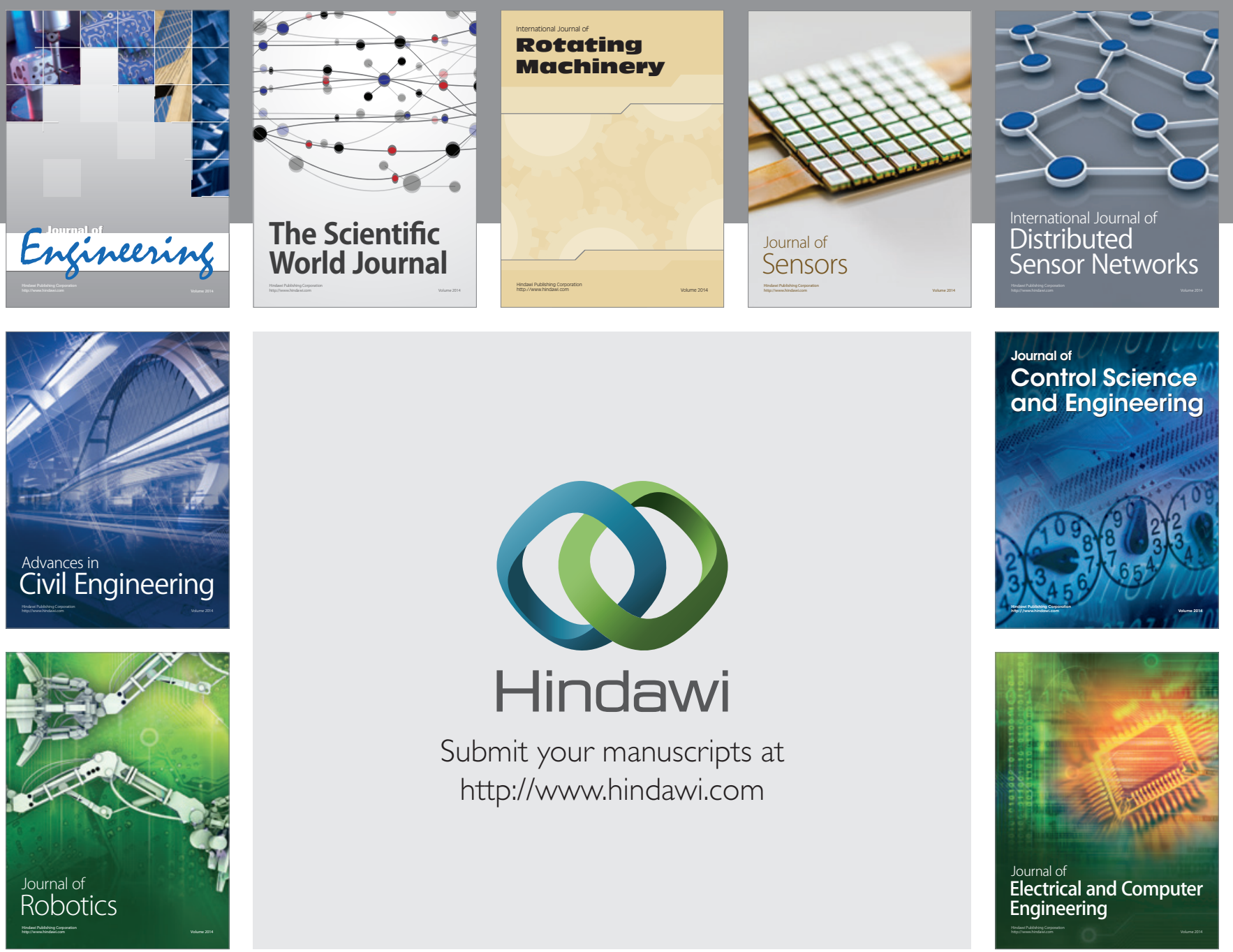

Submit your manuscripts at

http://www.hindawi.com
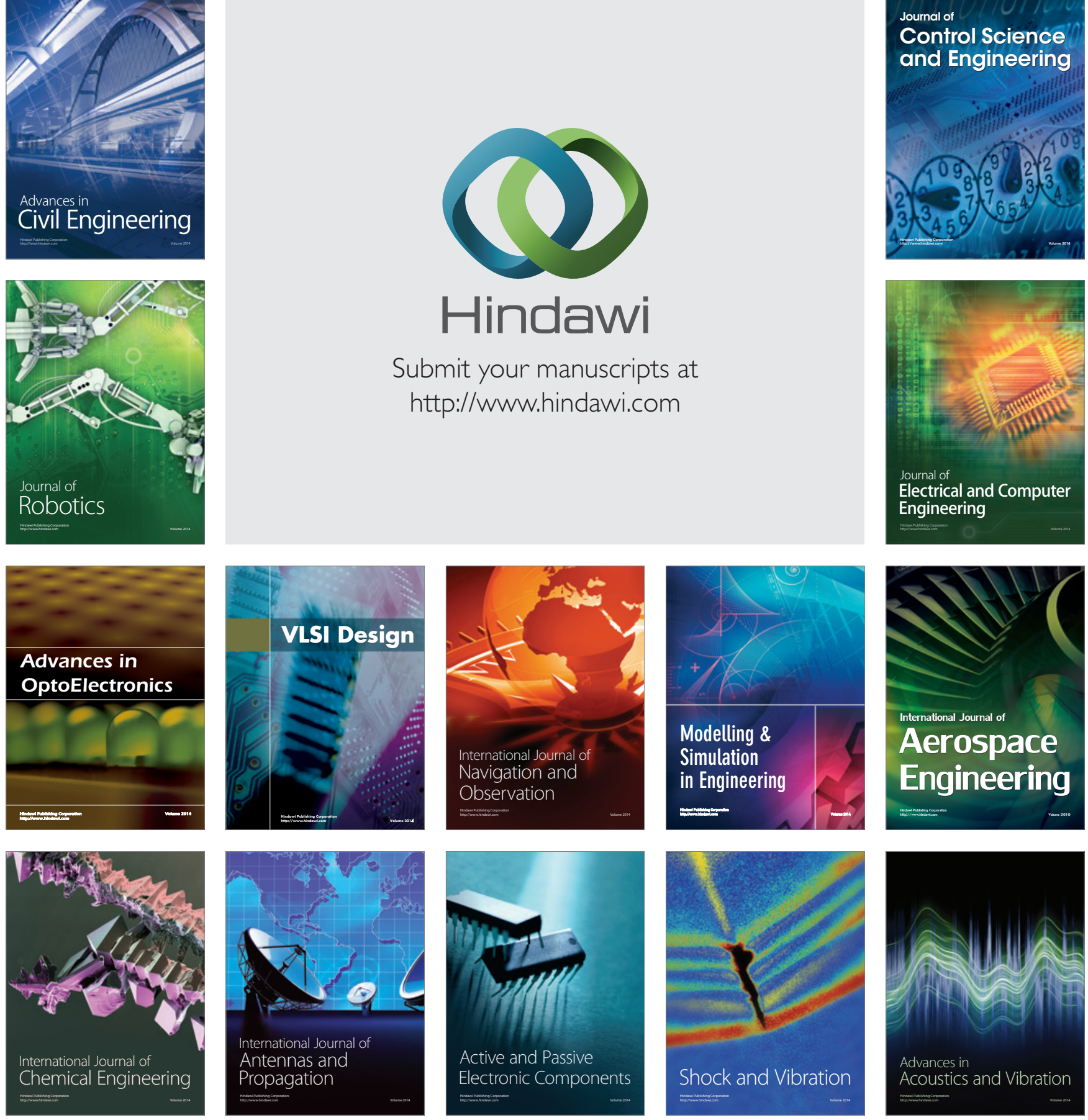